\title{
Awareness of Folic Acid Intake among Women in the Childbearing Age in Hail Region-Saudi Arabia
}

\author{
Murad Al-Holy ${ }^{1,2 *}$, Ala'a Eideh ${ }^{1}$, Suneetha Epuru ${ }^{1}$, Dima Abu-Jamous ${ }^{1}$, Ibrahim Ashankyty ${ }^{3}$ \\ ${ }^{1}$ Department of Clinical Nutrition College of Applied Medical Sciences, University of Hail, Hail, KSA; ${ }^{2}$ Department of Clinical Nu- \\ trition and Dietetics Faculty of Allied Health Sciences, Hashemite University, Zarqa, Jordan; ${ }^{3}$ Department of Clinical Laboratory \\ Sciences College of Applied Medical Sciences, University of Hail, Hail, KSA. \\ Email: *murad@hu.edu.jo
}

Received November $24^{\text {th }}$, 2012; revised December $24^{\text {th }}$, 2012; accepted January $3^{\text {rd }}, 2013$

\begin{abstract}
This study evaluated the awareness of folic acid, timing of folic acid supplementation and source of knowledge of folic acid intake in Hail region-Saudi Arabia. A sample of 300 married women in the childbearing age (19 - 45 years) in Hail in the period between October/2011 and January/2012 participated in a survey study regarding awareness and use of folic acid before and during pregnancy. Participant women were asked to respond to different questions related to age, level of education, occupation, monthly income, gravidity, and other information concerning folic acid awareness, specific knowledge, supplementation practices, and source of knowledge about the preconceptional intake of folic acid. While $91.0 \%$ of the subjects were aware of folic acid, $81.0 \%$ knew that folic acid could prevent neural tube defects and $84.0 \%$ of the subjects took folic acid prior or during a certain stage of pregnancy. Nonetheless, only $10.0 \%$ of the subjects who proclaimed that they know the proper timing for folic acid supplementation recognized that folic acid should be taken prior and during the first trimester of pregnancy. University education was the strongest predictor of folic acid knowledge and university educated subjects had significantly $(P<0.01)$ higher folic acid supplementation compared to subjects with lower educational level. Women with lower gravidity and those with planned pregnancies reported significantly $(P<0.05$, and $P<0.01$, respectively) higher folic acid supplementation. University education was the strongest predictor of folic acid knowledge. Health care providers were the main source of knowledge of folic acid education. It is recommended that health care professionals and media need to emphasize more on educating women about the importance of taking folic acid supplementation in the proper time.
\end{abstract}

Keywords: Folic Acid; Awareness; Supplementation; Saudi Arabia

\section{Introduction}

Neural tube defects (NTDs) are among the most serious congenital factors contributing to infant mortality and serious disability, occurring in over one quarter of a million newborns per year, worldwide. The two most common types of NTDs are anencephaly and spina bifida. A child with anencephaly cannot survive, and dies before birth or shortly afterwards. A child with spina bifida can survive, but often has serious functional abnormalities, and may be mentally retarded [1].

The discovery that the intervention by folic acid (FA) supplementation can prevent NTDs has granted the chance of essentially eliminating these common congenital defects, if the efforts to increase intake of FA are successful. Daily consumption of a supplement containing $400 \mu g$ of folic acid prior and during the first trimes-

\footnotetext{
*Corresponding author.
}

ter of pregnancy has been shown to be effective in preventing both the recurrence and occurrence of neural tube defects (NTDs) [2]. However, NTDs occur during days 22 - 28 of fetal development, before most women even know that they are pregnant, hence, initiating FA supplementation after the first month of pregnancy is considered too late to prevent NTDs. Thus, in 1992, the US Public Health Service recommended that all women capable of becoming pregnant consume at least $400 \mu \mathrm{g}$ of FA as a supplement daily [3]. The current recommended dietary allowances for pregnant women, or those planning pregnancy is $600 \mu \mathrm{g}$ daily [4]. Oakley (2002) estimated that globally, 500,000 children are born each year with spina bifida and anencephaly, two of the most common and severe birth defects [5]. Increased consumption of supplemental synthetic FA by fortification of staple foods will prevent approximately 375,000 of these birth defects each year [6]. 
Neural tube defects have a multifactorial etiology incorporating a combination of genetic and environmental factors, such as nutrition. It is now generally accepted that between $50 \%$ and $70 \%$ of affected births are preventable by maternal intake of sufficient FA before and during early pregnancy [7]. The unequivocal evidence for this is based on a substantial number of international trials and case control studies during the past two decades [7]. A large intervention study in China demonstrated protection against NTDs even with a relatively small dose of FA supplementation (0.4 mg per day) [8].

Up to our knowledge, no studies were undertaken to explore the level of awareness of FA supplementation among women in the childbearing age in Saudi Arabia (SA) and only a few studies addressed the prevalence of NTDs among newborn infants in SA. Despite the fact that fortification of flour with FA has remarkably decreased the occurrence of NTDs in SA $[9,10]$, the incidence rate of NTDs is still high [11,12]. In the Asir region-SA, the incidence rate of NTDs was $0.78 \%$. Surprisingly, only $25 \%$ of the 64 mothers who gave birth to babies with NTDs were on folate supplementation during the affected pregnancy and no one received preconceptional FA supplementation [11]. In another study, Kari et al. (2008) investigated the level of awareness among female college students (average age $=21$ years) about the importance of FA supplementation before conception in preventing NTDs [12]. Only $12 \%$ of the study group knew the importance of FA in preventing NTDs before undertaking intensive education program about FA for the subjects involved in the study. A previous study also indicated that the majority of women in the SA have poor knowledge scores of proper nutrition during pregnancy and lactation [13]. This necessitates exploring the prevalence of FA deficiency among women in the childbearing age and the level of awareness for FA supplementation preconceptionally as a primary hurdle against NTDs. The objectives of this study were to evaluate the awareness of the need for FA supplementation and the timing of FA intake for married women in the childbearing age. Additionally, to determine the source of knowledge of FA and the impact of educational level, income, and other factors on the intake and the timing of FA intake.

\section{Methods}

\subsection{Subjects Enrollment}

We conducted a survey study to evaluate the awareness of the need for FA supplementation for the married women during the childbearing age in the Hail region-SA in the period between October/2011 and January/2012. Three hundred women participated in the study. The study subjects were recruited mainly by making interviews with married women at the University of Hail campus, or by making arranged visits to some of the houses in Hail city or by meeting women at Hail maternity hospital. Subjects were women in the childbearing age, 19 - 45 years old, not pregnant and not using contraceptives or if pregnant in their first trimester. Participants were given idea about the study and were asked to sign consents as an agreement for participation. All women were informed that they have the right to refuse to participate. The identities of participating women were kept confidential. No identifying information was obtained on the survey so that the anonymity of participating women was protected.

\subsection{Definition of Awareness, Knowledge and Use of FA}

Before recruitment begins, researchers were trained to learn standardized interview methods. At the time of recruitment, researchers were given informed consent, and questionnaires to study participants to obtain demographic data and information about women's awareness of, knowledge about, and use of FA supplements. The researchers were also trained to address the questions properly and had a broad knowledge of the issue. FA awareness was defined as having ever read or heard of FA. Knowledge about FA was defined as knowing that FA prevents NTDs and timing was defined as knowing that FA should be taken preconceptionally and throughout the first trimester of pregnancy. FA use was defined as having ever taken FA supplements or multivitamins containing FA prenatally or during current pregnancy. Participant women in the childbearing age were asked to respond to a validated questionnaire composed of different questions related to age, level of education, occupation, monthly income, gravidity, and other information concerning FA awareness, specific knowledge, supplementation practices, and source of knowledge about the preconceptional intake of FA.

\section{Statistical Analysis}

The Statistical Package for Social Sciences (version 16.0, SPSS, Inc) was used for the statistical analysis of the data. Frequencies were calculated for qualitative data. ChiSquare tests were done to understand bi-variate associations. The criteria for statistical significance were either $P<0.05$ or $P<0.01$ with confidence interval of either $95 \%$ or $99 \%$, respectively. All reported $P$ values were made on the basis of 2-sided tests. The data set was cleaned and edited for inconsistencies before statistical analysis. Missing data were not statistically computed.

\section{Results}

Three hundred women in the childbearing age were in- 
terviewed to investigate their knowledge and supplementation practices of FA. The general characteristics of the study group are mentioned in Table 1. The subjects were women in the childbearing age. Most of the subjects $(>46 \%)$ were in the 26 - 35 years age category. The majority (58\%) of the subjects have received or currently enrolled in university education programs and most of them (85.7\%) have an average monthly income of more than 5000 SR (1400 US dollars). About half of the study group has two children or less, and the number of employed women was slightly more than half of the group. Table 2 shows the levels of awareness of FA intake, knowledge, and supplementation practices of the study subjects in relation to age, level of education, household monthly income, gravidity, employment status and early planning of pregnancy. The general awareness of FA was high, where $91 \%$ of the study subjects have heard or read about FA and $81 \%$ knew that FA has a role in preventing NTDs. Table 3 shows the response of the study group to the timing of FA intake. About $70 \%$ of the subjects who acknowledged of knowing of proper timing for FA supplementation believed that FA should be taken during the first trimester of pregnancy, whereas $41 \%$ responded that it should be taken preconceptionally, and only $10 \%$ of the subjects who have knowledge of FA indicated that it should be taken preconceptionally as well as during pregnancy. Regarding the source of knowledge for the participating subjects, generally most of the study group obtained their knowledge of FA intake from medical care providers $(77.7 \%)$, including physicians, nurse, dietitian, and midwives (Figure 1).

\section{Discussion}

Surprisingly, more than half of the study population has indicated that they planned in advance for their pregnancies (Table 1). Notwithstanding, planning for birth does not necessarily mean that the women made pre-pregnancy visits for their medical care provider or having enough knowledge of the importance of taking FA preconceptionally. In a study that involved surveying 320 primigravid women in Sydney-Australia for the use of FA before and during pregnancy, only $23.4 \%$ were found to have taken FA at least 1 month prior to conception and those of the study group who planned for their pregnancies, only $34.5 \%$ commenced FA prior to conception[14].

Although about $84 \%$ of the subjects reported having FA supplementation (Table 2), this does not mean that they have taken FA in the critical period of time crucial for preventing NTDs. More than half of the group reported that they are currently taking FA supplement. Of those who have knowledge of the importance of FA intake in preventing NTDs, the age group (26 - 35 years) corre- lated significantly $(P<0.01)$ with FA awareness, knowledge and supplementation compared to the other age groups ( $<25$ years and $36-45$ years). The level of education (university educated subjects) correlated significantly $(P<0.01)$ with awareness and knowledge of FA compared to less educated subjects (less than high school and high school education). Consequently, this knowledge was translated to real FA intake, where the university-educated women reported significantly $(P<$ 0.01) more supplementation of FA compared to the other groups. Likewise, the level of education among women in Texas-USA was also the strongest predictor of FA intake [15]. Additionally, only about $25 \%$ of 508 women in the childbearing age in Honduras actually knew of the importance of FA in preventing NTDs and consumed it during the proper time. Poor educational level signifi-

Table 1. General characteristics of the study population $(\mathrm{N}=300)$.

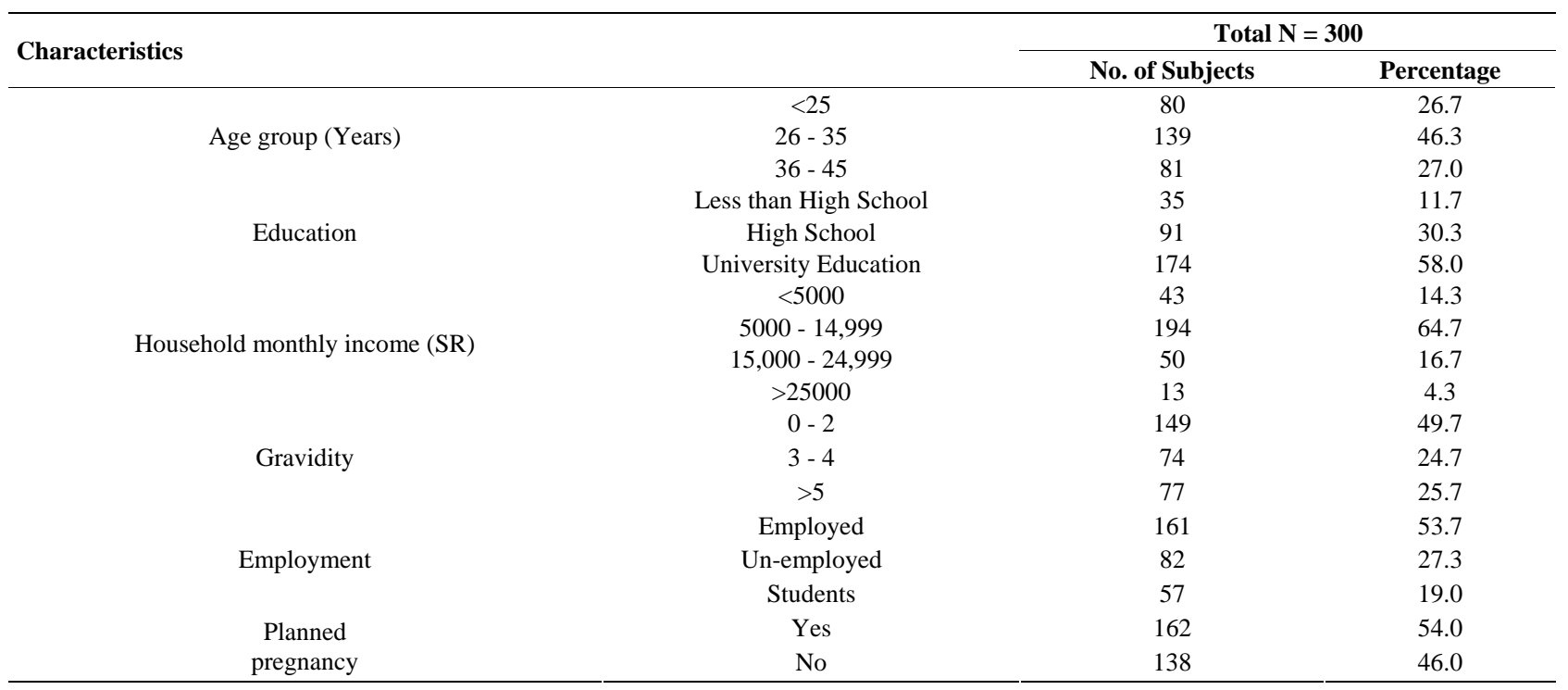


Table 2. Awareness of folic acid, specific knowledge and practices for women in the childbearing age in Hail region-SA in relation to age, education, income, gravidity, employment status and planning for pregnancy. The values were expressed as number of subjects followed by percentage in parenthesis.

\begin{tabular}{|c|c|c|c|c|c|c|}
\hline \multicolumn{2}{|c|}{ Parameter (No. of Subjects) } & \multirow{2}{*}{$\begin{array}{c}\begin{array}{c}\text { Ever heard } \\
\text { or read about }\end{array} \\
\text { FA }\end{array}$} & \multirow{2}{*}{$\begin{array}{l}\text { Heard or read } \\
\text { FA prevents } \\
\text { NTDs }\end{array}$} & \multirow{2}{*}{$\begin{array}{c}\text { Ever taken FA } \\
\text { supplements }\end{array}$} & \multirow{2}{*}{$\begin{array}{c}\text { Currently under FA } \\
\text { supplementation }\end{array}$} & \multirow{2}{*}{$\begin{array}{l}\text { No. of miscarriages } \\
\text { and births of neural } \\
\text { tube defects }\end{array}$} \\
\hline & & & & & & \\
\hline \multirow[t]{2}{*}{ All participants } & $(300)$ & $273(91.0)$ & $243(81.0)$ & $253(84.3)$ & $153(51.0)$ & $8(2.7)$ \\
\hline & $<25$ yr $(80)$ & $67(83.8)$ & $62(77.5)$ & $58(72.5)$ & $42(52.5)$ & $0(0.0)$ \\
\hline \multirow{2}{*}{$\begin{array}{c}\text { By age } \\
\text { group (Year) }\end{array}$} & $26-35$ yr (139) & $136(97.8)$ & $124(89.2)$ & $129(92.8)$ & $81(58.3)$ & $2(1.4)$ \\
\hline & $36-45$ yr (81) & $70(86.4)$ & $57(70.4)$ & $66(81.5)$ & $30(37.0)$ & $6(7.4)$ \\
\hline \multirow[t]{2}{*}{$\begin{array}{l}\text { Chi- Square } \\
\text { Value }\end{array}$} & & $15.154^{* *}$ & $12.669^{* *}$ & $16.529^{* *}$ & $9.334^{* *}$ & $10.013^{* *}$ \\
\hline & Less than high school (35) & $28(80.0)$ & $18(51.4)$ & $27(77.1)$ & $15(42.9)$ & $3(8.6)$ \\
\hline \multirow{2}{*}{$\begin{array}{c}\text { By } \\
\text { education }\end{array}$} & High school (91) & $75(82.4)$ & $68(74.7)$ & 67 (73.6) & 45 (49.5) & $3(3.3)$ \\
\hline & University education (174) & $170(97.7)$ & $157(90.2)$ & $159(91.4)$ & $93(53.4)$ & $2(1.1)$ \\
\hline \multirow[t]{2}{*}{$\begin{array}{l}\text { Chi- Square } \\
\text { Value }\end{array}$} & & $22.895^{* *}$ & $31.847^{* *}$ & $15.804^{* *}$ & 1.433 & $6.384^{*}$ \\
\hline & $<5000(43)$ & $(95.3)$ & $37(86.0)$ & $38(88.4)$ & $24(55.8)$ & $3(7.0)$ \\
\hline \multirow{3}{*}{$\begin{array}{l}\text { By household } \\
\text { monthly } \\
\text { income (SR) }\end{array}$} & 5000 - 14,999 (194) & $177(91.2)$ & $161(83.0)$ & $165(85.1)$ & $102(52.6)$ & $5(2.6)$ \\
\hline & $15,000-24,999(50)$ & $42(84.0)$ & $34(68.0)$ & $37(74.0)$ & $22(44.0)$ & $0(0.0)$ \\
\hline & $>25,000(13)$ & $13(100.0)$ & $11(84.6)$ & $13(100.0)$ & $5(38.5)$ & $0(0.0)$ \\
\hline \multicolumn{2}{|l|}{ Chi-Square Value } & 5.283 & 6.812 & 7.063 & 2.390 & 4.810 \\
\hline \multirow{3}{*}{ Gravidity } & $0-2(149)$ & 133 (89.3) & $123(82.6)$ & $120(80.5)$ & $81(54.4)$ & $1(0.7)$ \\
\hline & $3-4(74)$ & $72(97.3)$ & 66 (89.2) & 68 (91.9) & $42(56.8)$ & $0(0.0)$ \\
\hline & $>5(77)$ & $68(88.3)$ & $54(70.1)$ & $65(84.4)$ & $30(39.0)$ & $7(9.1)$ \\
\hline \multirow[t]{2}{*}{ Chi-Square Value } & & 4.812 & 9.369 & 4.826 & $6.121^{*}$ & $16.557^{* *}$ \\
\hline & Employed (161) & $160(99.4)$ & $146(90.7)$ & 147 (91.3) & $85(52.8)$ & $5(3.1)$ \\
\hline \multirow[t]{2}{*}{ Employment } & Un-employed (82) & $69(84.1)$ & $55(67.1)$ & $66(80.5)$ & 35 (42.7) & $3(3.7)$ \\
\hline & Students (57) & $44(77.2)$ & $42(73.7)$ & $40(70.2)$ & 33 (57.9) & $0(0.0)$ \\
\hline \multicolumn{2}{|l|}{ Chi- Square Value } & $31.772^{* *}$ & $22.126^{* *}$ & $15.487^{* *}$ & 3.562 & 1.992 \\
\hline \multirow{2}{*}{ Planned pregnancy } & Yes & $147(90.7)$ & $139(85.8)$ & $141(87.0)$ & $94(58.0)$ & $3(1.9)$ \\
\hline & No & $126(91.3)$ & $104(75.4)$ & $112(81.2)$ & $59(42.8)$ & $5(3.6)$ \\
\hline Chi- Square Value & & 0.029 & $5.278^{*}$ & 1.948 & $6.954^{* *}$ & 0.901 \\
\hline
\end{tabular}

"Significantly different at $P<0.05 ;{ }^{* *}$ Significant different at $P<0.01$.

cantly correlated with poor knowledge of FA function and its preconceptional consumption [16]. Apparently, family income did not correlate with awareness and knowledge FA intake and supplementation. Knowledge of the importance of FA intake in the prevention of NTD was inversely correlated with gravidity. Current supplementation status of FA was significantly $(P<0.05)$ higher among women with lower number of children $(0$ 2 children) compared to women with more than three children.

Proper timing of FA supplementation is vitally important for normal development of the nervous system of the embryo. Most of the time, women start FA supplementa- tion right after making their first visit to the clinic in response to a suspected pregnancy. By this time, they are two or three weeks through pregnancy, consequently missing the critical period for FA supplementation which is important for normal development of the neural tube.

Only $10 \%$ of the subjects who have knowledge of FA indicated that it should be taken preconceptionally as well as during pregnancy (Table 3). This finding agrees with the results of the study conducted in Texas-USA, in which about 1200 women in the childbearing age were surveyed for their knowledge and real intake of FA. Although $78 \%$ of the surveyed women knew about FA, only 33\% took it as a supplement and 25\% took it 
Table 3. Knowledge about timing of FA supplementation and source of knowledge $(\mathrm{N}=169)$. The values were expressed as number of subjects followed by percentage in parenthesis.

\begin{tabular}{|c|c|c|c|c|}
\hline \multicolumn{2}{|c|}{ Timing of folic acid } & $\begin{array}{l}\text { Need to take FA during } \\
\text { first } 3 \text { months of pregnancy }\end{array}$ & $\begin{array}{l}\text { Need to take FA before } \\
\text { and during pregnancy }\end{array}$ & $\begin{array}{l}\text { Need to take FA } \\
\text { before pregnancy }\end{array}$ \\
\hline \multicolumn{2}{|c|}{ Do you know when to take FA 169 (56.3) } & $118(69.8)$ & $10(5.9)$ & $41(13.7)$ \\
\hline \multirow{4}{*}{ Source of knowledge of FA } & Medical care provider & $95(80.5)$ & $9(90.0)$ & $29(70.7)$ \\
\hline & Media & $17(14.4)$ & 0 & $6(14.6)$ \\
\hline & Others & $0(0.0)$ & 0 & $1(2.4)$ \\
\hline & 2 or more sources & $6(5.1)$ & $1(10.0)$ & $5(12.2)$ \\
\hline
\end{tabular}

*Chi-square test for knowledge of timing to take FA and source of knowledge not statistically significant.

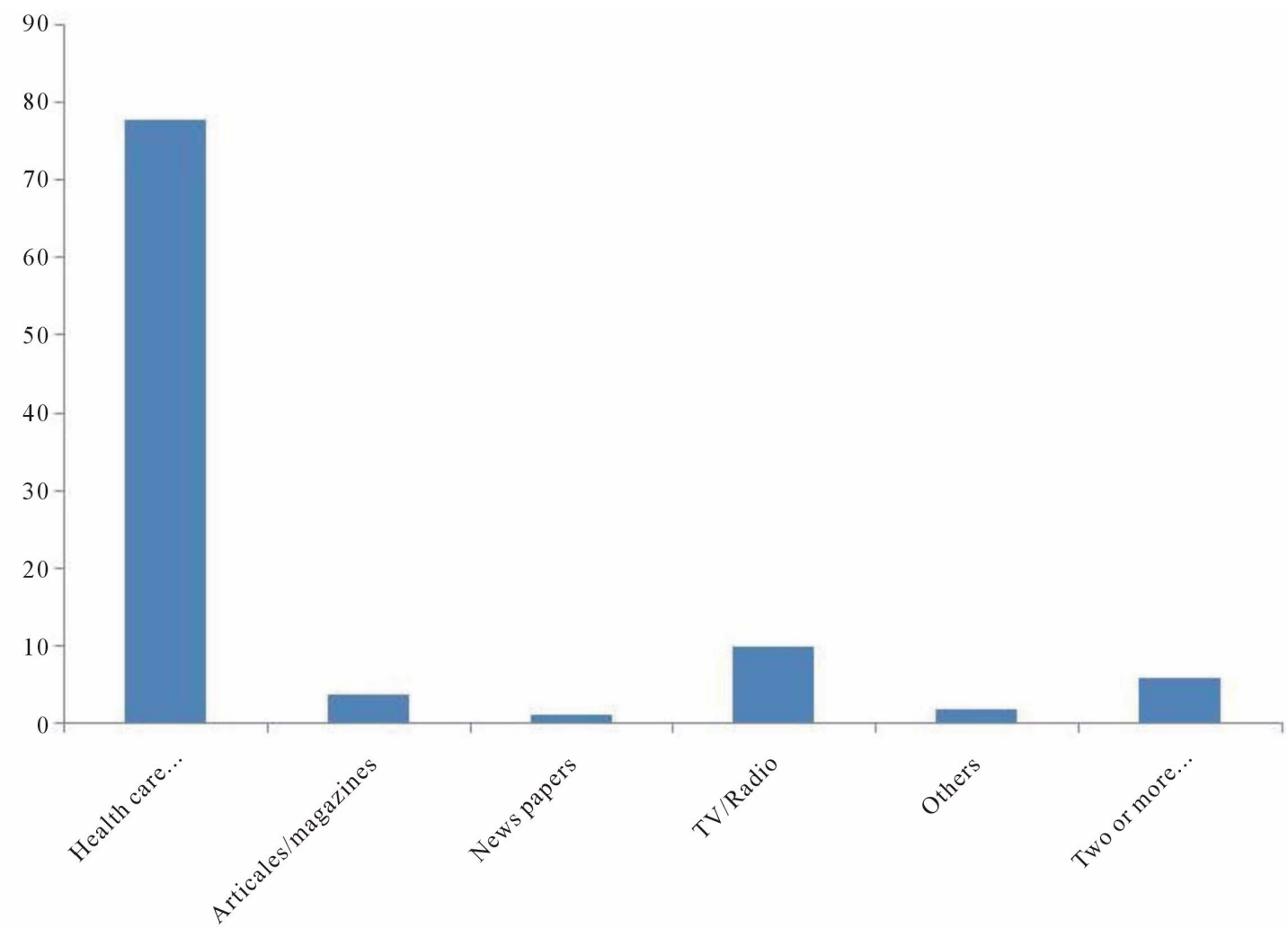

Figure 1. Contribution (\%) of different sources to the knowledge of folic acid among women in the childbearing age in Hail region-SA.

preconceptionally [15]. The timing of FA intake is crucially important. The closure of the neural tube is an early embryonic event that takes place over approximately $48 \mathrm{~h}$ and is completed by about day 28 of gestation. NTDs occur when this process malfunctions in any respect. Several forms of lesion can result from the ensuing damage, including anencephaly (involving some $40 \%$ of cases where the cranium is affected), and spina bifida (comprising about $50 \%$ of cases where the spinal cord is affected) and a small number of rare forms. Closure of the neural tube is thought to occur by a multi site process, thus combinations of these lesions may also be present in the more severely affected cases. NTDs are the largest group of anomalies of the central nervous system and are a major cause of morbidity and mortality in infants, worldwide. Anencephaly is a lethal disorder, with all affected cases dying either in uterus or shortly after birth [7].

FA supplementation appears to correct a disturbance in folate metabolism rather than a shortage of dietary folate. While it is accepted that maternal folate deficiency is not, per se, the underlying cause of neural tube defects, lower plasma and red cell folate concentrations have been observed in mothers carrying affected fetuses [17], and the risk of having an affected child was shown to be inversely proportional to maternal early pregnancy red cell 
folate concentration [18]. These observations provide support for a mechanism whereby relatively common polymorphisms in folate related receptors, binding proteins, enzymes, or other tissue specific gene products, in combination with comparatively small changes in nutrient status, can adversely affect the availability, metabolism or distribution of intermediates in pathways that are crucial to neural tube closure. Sadler (1998) suggested that FA is important for DNA synthesis and/or methylation of macromolecules, such as DNA and protein [19].

Health care providers were the major source for the knowledge and proper timing of FA intake. This source of knowledge impacted FA intake more significantly ( $P$ $<0.01$ ) compared to other sources. The other sources of knowledge such as reading articles, TV or radio health programs, or through browsing the internet or other sources of knowledge had only a slight influence on awareness and knowledge of FA (Figure 1).

Ren et al. (2006) indicated that the levels of FA awareness, knowledge and use among Chinese women living in a high NTD prevalence area during early pregnancy were very low and folate deficiency was quite prevalent [20]. Preconceptional FA supplementation $(0.4 \mathrm{mg} /$ day or more) to pregnant women who experienced NTD-affected pregnancies was successful in preventing recurrent NTDs in Mexican-American women [21]. On the other hand, other study in North Carolina failed to reveal the effect of multivitamin FA supplementation, or dietary folate on the incidence of NTDs. This was attributed to the prevalence of food fortification with FA and increasing use of multivitamins, which was accompanied by declining NTDs [22]. In Ontario-Canada, after adopting a policy of fortifying most cereal grains with FA, the prevalence of NTDs declined from 1.13 per 1000 pregnancies before fortification to 0.58 per 1000 pregnancies thereafter [23]. In the United States, blood folate levels increased significantly after food fortification was mandated in 1998, coinciding with a remarkable decline in NTDs birth prevalence [24]. However, Oakley, (2008) indicated that the prevention of infantile paralysis caused by maternal deficiency of FA is still poor and more preventive measures are necessary to maximize the prevention of FA preventable NTDs [25].

\section{Conclusion}

From the finding of the current study, apparently, the participants showed a good knowledge of the importance of FA supplementation as an effective tool to prevent NTDs. However, there is a gap between knowing and doing. The great majority of the subjects failed to know the proper time for FA acid supplementation. Higher levels of education and lower number of births correlated with better knowledge and better timing of FA supple- mentation. National and local campaigns may be necessary to promote more knowledge of FA supplementation and timing of intake. Additionally, the role of health care providers such as dietitians, midwives, and gynecologists is crucial in spreading the message of FA supplementation among women in the childbearing age.

\section{REFERENCES}

[1] M. Karin, K. M. van der Pal-de Bruin, P. G. Heijden, S. E. Buitendijk and L. D. Ouden, "Periconceptional Folic Acid Use and the Prevalence of Neural Tube Defects in the Netherlands," European Journal of Obstetrics, Gynecology and Reproductive Biology, Vol. 108, No. 1, 2003, pp. 33-39. doi:10.1016/S0301-2115(02)00362-7

[2] MRC Vitamin Study Research Group, "Prevention of Neural Tube Defects: Results of the Medical Research Council Vitamin Study,” Lancet, Vol. 338, No. 8760, 1991, pp. 131-137. doi:10.1016/0140-6736(91)90133-A

[3] Centers for Disease Control and Prevention, "Recommendations for the Use of Folic Acid to Reduce the Number of Cases of Spina Bifida and Other Neural Tube Defects," Morbidity and Mortality Weekly Report, Vol. 41, 1992, pp. 1-7.

[4] S. R. Rolfes, K. Pinna and E. N. Whitney, "Understanding Normal and Clinical Nutrition,” 6th Edition, Wadsworth, Belmont, 2009.

[5] G. P. Oakley, "Inertia on Folic Acid Fortification: Public Health Malpractice,” Teratology, Vol. 66, No. 1, 2002, pp. 44-54. doi:10.1002/tera.10079

[6] C. M. Cornel, D. J. de Smit and L. T. W. de Jong, "Folic Acid-The Scientific Debate as a Base for Public Health Policy,” Reproductive Toxicology, Vol. 20, No. 3, 2005, pp. 411-415. doi:10.1016/j.reprotox.2005.03.015

[7] A. M. Molloy, "The Role of Folic Acid in the Prevention of Neural Tube Defect," Trends in Food Science and Technology, Vol. 16, No. 6-7, 2005, pp. 241-245. doi:10.1016/j.tifs.2005.03.009

[8] R. J. Berry, Z. Li, J. D. Erickson, S. Li, C. A. Moore and H. Wang, et al, "Prevention of Neural-Tube Defects with Folic Acid in China. China-US Collaborative Project for Neural Tube Defect Prevention,” New England Journal of Medicine, Vol. 341, 1999, pp. 1485-1490. doi:10.1056/NEJM199911113412001

[9] O. Y. Safdar, A. A. Al-Dabbagh, W. Abuelieneen and J. A. Kari, "Decline in the Incidence of Neural Tube Defects after the National Fortification of Flour (19972005)," Saudi Medical Journal, Vol. 28, No. 8, 2007, pp. 1227-1229.

[10] M. D. Al-Mendalawi and J. A. Kari, "Folic Acid Awareness among Female College Students. Neural Tube Defect Prevention,” Saudi Medical Journal, Vol. 30, No. 5, pp. 723-724.

[11] A. Asindi and A. Al-Shehri, "Neural Tube Defects in the Asir Region of Saudi Arabia,” Annals of Saudi Medicine, Vol. 21, No. 1-2, pp. 26-29.

[12] J. A. Kari, E. S. Bardisi, R. M. Baitalmal and G. A. 
Ageely, "Folic Acid Awareness among Female College Students: Neural Tube Defects Prevention," Saudi Medical Journal, Vol. 29, 2008, pp. 1749-1751.

[13] A. A. Mansour and S.A. Hassan, "Factors that Influence Women's Nutrition Knowledge in Saudi Arabia," Health Care for Women International, Vol. 15, No. 3, 1994, pp. 213-223.

[14] D. C. Wilton and M. J. Foureur, "A Survey of Folic Acid Use in Primigravid Women,” Women and Birth, Vol. 23, No. 2, 2010, pp. 67-73. doi:10.1016/j.wombi.2009.09.001

[15] M. A. Canfield, S. M. Przybyla, P. A. Case, T. Ramadhani, L. Suarez and J. Dryer, "Folic Acid Awareness and Supplementation among Texas Women of Childbearing Age," Preventive Medicine, Vol. 43, No. 1, 2006. pp. 2730. doi:10.1016/j.ypmed.2006.01.022

[16] D. Y. Wu, G. Brat, G. Milla and J. Kim, “Knowledge and Use of Folic Acid For Prevention of Birth Defects amongst Honduran Women," Reproductive Toxicology, Vol. 23, No. 4, 2007, pp. 600-606. doi:10.1016/j.reprotox.2007.01.010

[17] P. N. Kirke, A. M. Molloy, L. E. Daly, H. Burke, D. G. Weir and J. M. Scott, "Maternal Plasma Folate and Vitamin B12 Are Independent Risk Factors for Neural Tube Defects,” The Quarterly Journal of Medicine, Vol. 86, 1993, pp. 703-708.

[18] L. E. Daly, P. N. Kirke, A. Molloy, D. G. Weir and J. M. Scott, "Folate Levels and Neural Tube Defects: Implications for Prevention," Journal of American Medical Association, Vol. 274, No. 21, 1995, pp. 1698-1702. doi:10.1001/jama.1995.03530210052030

[19] T. W. Sadler, "Mechanisms of Neural Tube Closure and Defects," Mental Retardation and Development, Vol. 4, No. 4, 1998, pp. 247-253.
doi:10.1002/(SICI)1098-2779(1998)4:4<247::AID-MRD D3>3.0.CO;2-P

[20] A. Ren, L. Zhang, Z. Li, L. Hao, Y. Tian and Z. Li, "Awareness and Use of Folic Acid, and Blood Folate Concentrations among Pregnant Women in Northern China-An Area with a High Prevalence of Neural Tube Defects," Reproductive Toxicology, Vol. 22, 2006, pp. 431-436.

[21] M. Felkner, L. Suarez, K. Hendricks and R. Larsen, "Implementation and Outcomes of Recommended Folic Acid Supplementation in Mexican-American Women with Prior Neural Tube Defect-Affected Pregnancies,” Preventive Medicine, Vol. 40, No. 6, 2005, pp. 867-871. doi:10.1016/j.ypmed.2004.10.006

[22] S. J. Thompson, M. E. Torres, R. E. Stevenson, J. H. Dean and R. G. Best, "Periconceptional Multivitamin Folic Acid Use, Dietary Folate, Total Folate and Risk of Neural Tube Defects in South Carolina," Annals of Epidemiology, Vol. 13, No. 6, 2003, pp. 412-418. doi:10.1016/S1047-2797(02)00460-X

[23] J. G. Ray, C. V. Meier, M. J. Cermeulen, S. Boss, P. R. Wyatt and D. E. Cole, "Association of Neural Tube Defects and Folic Acid Food Fortification in Canada," Lancet, Vol. 360, No. 9350, 2002, pp. 2047-2048. doi:10.1016/S0140-6736(02)11994-5

[24] R. S. Olney and J. Mulinare, "Trends in Neural Tube Defect Prevalence, Folic Acid Fortification, and Vitamin Supplement Use,” Seminars in Perinatology, Vol. 26, No. 4, 2002, pp. 277-285. doi:10.1053/sper.2002.34773

[25] G. P. Oakley, "Elimination of Folic Acid Preventable Neural Tube Defects," American Journal of Preventive Medicine, Vol. 35, No. 6, 2008, pp. 606-607. doi:10.1016/j.amepre.2008.09.017 